\title{
ELEMENTOS DA TEORIA DOS JOGOS NO PROCESSO DE REPRIVATIZAÇÃO DA TAP (GAME THEORY ELEMENTS AT TAP RE-PRIVATIZATION PROCESS)
}

\author{
Renata dos Santos Constant ${ }^{1}$ \\ Deivison da Silveira Pereira ${ }^{2}$ \\ Sônia Regina Brantes ${ }^{3}$ \\ João Carlos Correia Baptista Soares de Mello ${ }^{4}$
}

Resumo: Este artigo tem como objetivo discutir os aspectos da Teoria dos Jogos no processo de reprivação da TAP. Este processo iniciou em 2014, e envolveu além do Governo Português, que fiscalizou o processo, quatro consórcios, que disputavam o controle de $61 \%$ da empresa. A Teoria dos Jogos é um ramo da matemática que analisa o processo de decisão com base nas informações que estão (ou não) disponíveis a cada jogador. Neste cenário, aanálise do processo de privatização com base na Teoria dos Jogos se faz importante, pois busca entender o papel e a influência de cada jogador dentro do processo de decisão.

Palavras-Chave: Teoria dos Jogos, TAP, Aviação.

Abstract: This article aims to discuss game theoryaspects in TAPre-privatization process. This process began in 2014 and involved beyond the Portuguese government, which oversaw the process four consortia vying for control of $61 \%$ of the company. The Game Theory is a branch of mathematics that analyzes the decision-making process based on the information that is (or not) available to each player. In this scenario, the analysis of the privatization process based on game theory becomes important because it seeks to understand the role and influence of each player within the decision making process.

Key words: Game Theory, TAP, Aviation.

\footnotetext{
${ }^{1}$ Universidade Federal Fluminense, renata.constant@ hotmail.com

${ }^{2}$ Universidade Federal Fluminense, dspereira@id.uff.br

${ }^{3}$ Universidade Federal Fluminense, soniareginabrantes@ hotmail.com

${ }^{4}$ Universidade Federal Fluminense, joaocsmello@ gmail.com
} 


\section{INTRODUÇÃO}

A TAP (Transportes Aéreos Portugueses) foi fundada em 14 de março de 1945 como um serviço especial a ser prestado pelo Secretariado da Aeronáutica Civil (SAC), com o objetivo de regulamentar e controlar as atividades da aviação civil. Apenas em 19 de Setembro de 1946 entrou em operação, com a inauguração das duas primeiras linhas aéreas: Lisboa-Madrid e LisboaLuanda-Lourenço Marques. (Coutinho et al, 2013)

De acordo com o site da TAP, atualmente a empresa é considerada a principal companhia aérea portuguesa e líder na operação entre a Europa e o Brasil, operando uma média de 2500 voos por semana, ligando 35 países através de 84 destinos, e tendo uma frota composta por 77 aviões.

O processo de privatização não é novo na história da TAP. Em 1 de junho de 1953 o serviço especial TAP foi extinto e criada uma empresa de mesmo nome, a TAP Sociedade Anônima de Responsabilidade Limitada, com capital misto, no entanto com a maioria do Estado. No entanto, em 15 de abril de 1975, com a onda de nacionalização da Revolução de Abril, a TAP é tornada uma empresa pública. (Coutinho et al, 2013)

O novo processo de privatização teve seu início em 2012, segundo o site Observador quando a empresa atingia um prejuízo técnico de 381 milhões de euros. Ao final de 2012 o processo foi cancelado pelo Governo Português, através da recusa da proposta apresentada pelo único candidato Gérman Efromovich (presidente do grupo Synergy Aerospace, que controla a Avianca, entre outras), de acordo co o governo devido à falta de cumprimento de alguns requisitos previstos no caderno de encargos do processo. Ao final de 2014 o processo de privatização foi remodelado e, após a disputa entre quatro interessados, e duas rodadas, em Junho de 2015, o processo de privatização foi finalizado chegando a um vencedor.

A privatização da TAP foi um dos assuntos mais polêmicos nos jornais de todo o mundo, pois, apesar de já ter sido definido o vencedor, algumas instituições ainda buscam anular o processo de privatização. Estudos anteriores utilizam elementos da Teoria dos Jogos para avaliar o comportamento estratégico das empresas, como Shi, X.e Voß (2011) que verificam aspectos da Teoria de Jogos para modelar e analisar a indústria naval. Nesse sentido, o objetivo deste trabalho é analisar o processo de reprivatização da TAP, com base na Teoria de Jogos, considerando de um lado o governo; que estabelece os critérios da concorrência; e do outro as empresas competidoras; que elaboram suas propostas.

$\mathrm{Na}$ seção 2 é apresentado o processo de reprivatização.Na seção 3 é feita uma revisão da literatura da Teoria dos Jogos. Por fim, na seção 4 é realizada a análise do jogo, com base nos principios de Teoria dos Jogos para o processo de privatização.

\section{$2 . \quad$ PROCESSO REPROVATIZAÇÃO DA TAP}

Através do Decreto Lei 210/2012, o Governo Português aprovou o início da $3^{\mathrm{a}}$ e $4^{a}$ fase do processo de reprivativação da TAP, buscando segundo esta lei promover a competitividade da economia portuguesa. Este processo culminou, conforme descrito na Resolução 88B/2012, com a aprovação da Synergy Aerospace para participação na oferta de venda. No entanto, a Resolução 102/2012 suspendeu o processo e desconsiderou a proposta enviada por verificar que não havia elementos conclusivos para aprovação do proponente.

A reabertura do processo através do Decreto Lei 181-A/2014, revogando o Decreto Lei 210/2012, e atendendo à condicionantes do Programa de Assistência Econômica acordado com o a União Européia, Fundo Monetário Internacional e o Banco Central Europeu, estabeleceu a venda direta de ações da TAP considerando que o adquirente representará $61 \%$ do capital social da TAP, aos trabalhadores serãodestinados $5 \%$ da companhia e os $34 \%$ restantes 
ficarão estabelecidos como opção de venda em favor do Governo em até 2 anos, total ou parcialmente. Dentre outras diretrizes, ressalta-se o Art. $10^{\circ}$ onde estabelece ao Conselho de Ministros poderes para em qualquer momento suspender o processo de venda.

\subsection{TERMOS E CONDIÇÕES}

A venda conforme a Resolução 4A/2015 destina-se a proponentes nacionais portugueses ou estrangeiros, respeitando os limites impostos pela legislação da União Européia onde é vedada a participação majoritária de um não europeu em uma companhia aérea européia. Os critérios de seleção utilizados são:

- Contribuição para reforço da capacidade econômico-financeira da TAP;

- Valor apresentando para aquisição das ações;

- Plano estratégico, preservando a marca TAP, sua associação à Portugal com sede e direção efetiva em solo português;

- Preservação das ligações entre os principais territórios portugueses e as regiões autônomas;

- Manutenção do hub em Lisboa;

- Experiência no setor de aviação;

- Respeito aos acordos coletivos vigentes;

$\mathrm{O}$ processo de escolha segundo a Resolução 4-A/2015 estabelece no seu Art. $14^{\circ}$ que o Conselho de Ministro poderá selecionar uma ou mais propostas de aquisição. Destacando que o Conselho de Ministro pode realizar uma fase de negociação para equalização e melhoria nas propostas, sendo que a decisão final pode também determinar pela suspensão do processo de venda.

\subsection{PROCESSO DE ESCOLHA}

O processo de escolha iniciou com Despacho 1156/2015 onde se estabeleceu a comissão especial deste processo. E no Despacho 1469-A/2015 determinou o início em 11 de Fevereiro de 2015 as diligências informativas com prazo para envio das propostas até 15 de Maio de 2015. As garantias bancárias foram exigidas em sequência no Despacho 5119-C/2015.

Através da Resolução 32-A/2015, o Conselho de Ministro verificou as propostas apresentadas recusando a proposta da Quifel, por não atender aos requisitos, e determinou uma rodada de negociação entre outras duas propostas apresentadas, sendo estas feitas pela SAGEF (consórcio entre a Synergy Aerospace Corp e Germán Efromovich) e a Gateway (consórcio entre a DGN Corporation e o grupo português HPGB).

O Despacho 5638-A/2015 estabeleceu o período de negociação e determinou o envio das propostas finais até o dia 05 de Junho de 2015. A Resolução 38-A/2015 determinou como vencedor do processo o consórcio Gateway para aquisição de $61 \%$ do capital social da TAP.

\section{TEORIA DOS JOGOS}

A Teoria dos Jogos é um ramo da matemática que estuda o processo de tomadas de decisões de agentes racionais (jogadores), em situação de interação estratégica. Para Fiani (2009), uma interação estratégica é aquela em que os agentes, indivíduos ou organizações, reconhecem a interdependência mútua de suas decisões e um agente racional é um jogador com capacidade de decisão para afetar os demais e emprega os meios mais adequados para alcançar os objetivos que almeja. A Teoria dos Jogos é aplicada em diversos campos como: economia, filosofia, ciências políticas, ciências militares, entre outros.

\subsection{ELEMENTOS}

Os jogos podem ser analisados sob diferentes enfoques:

Quanto à sequência das jogadas:

- Jogos simultâneos ou jogos seqüenciais 
Quanto às informações que cada agente possui sobre as tomadas de decisões do outro:

- Jogos de informação perfeita ou de informação imperfeita

- Jogos de informação completa ou de informação incompleta

- Jogos de informação simétrica ou de informação assimétrica

Quanto à cooperação entre os agentes:

- Jogos cooperativos ou não cooperativos

Um jogo é sequencial e de informação perfeita, quando o processo de interação estratégica se desenvolve em etapas sucessivas, em uma ordem predeterminada, e sempre que um jogador se move ele conhece tudo que cada jogador observou ou fez em cada momento anterior do jogo (Myerson, 1991). Quando no momento de tomada de decisão cada jogador desconhece as decisões dos demais jogadores este é um jogo simultâneo e de informação imperfeita. Vale ressaltar que a simultaneidade não se refere ao tempo em que são tomadas as decisões, mas ao fato de que as decisões de cada jogador, naquele ponto do jogo não são de conhecimento dos demais.

Um jogo de informação completa é aquele em que as recompensas resultados possíveis - dos jogadores são de conhecimento comum. Uma informação é dita de conhecimento comum quando todos os jogadores conhecem a informação, todos os jogadores sabem que todos os jogadores conhecem a informação, todos os jogadores sabem que todos os jogadores sabem que todos os jogadores conhecem a informação e assim por diante, até o infinito (Fiani, 2009).

\subsection{LEILÕES}

Um leilão é o caso de um jogo simultâneo de informação incompleta. $\mathrm{O}$ leiloeiro busca obter pelo objeto leiloado o melhor resultado possível e cada arrematador conhece quanto o objeto leiloado vale para ele, caso vença o leilão.

Cada leilão tem seu conjunto de regras e sua forma.

No conjunto de regras de um leilão podem ser estabelecidos: quem pode realizar lances,como esses lances podem ser efetuados, que tipo de lance pode ser aceito, como o leilão se desenvolve, como o vencedor é determinado, etc.

O leilão pode ser:

- De oferta, de demanda ou duplo;

- Aberto ou fechado;

- Lance mínimo ou não;

- Envelope lacrado ou oral;

- Lances ascendentes ou decrescentes;

- Lances simultâneos;

- Leilão de primeiro preço ou de segundo preço (leilão de Vickrey);

- Leilão de uma unidade ou múltiplas unidades;

- Valor comum ou valor privado;

\section{ANÁLISE DO PROCESSO DE REPRIVATIZAÇÃO DA TAP}

Em um jogo de informações assimétricas, os jogadores tomam suas decisões em sequência e possuem informações privadas. Uma informação privada é aquela que não é de conhecimento de todos os jogadores, como no caso estudado.

A Figura 1 apresenta o diagrama com a sequência de decisões do processo de reprivatização da TAP.

Analisando a Figura 1 com base nos conceitos de Teoriados Jogos descritos na seção 3, pode-se observar que, com relação a sequencia de jogadas, o processo de privatização da TAP é um jogo simultâneo, pois as empresas concorrentes colocam suas propostas ao mesmo tempo não sabendo da entrega das propostas das outras empresas.

Através da Figura 2, podem-se perceber dois cenários distintos no que tange à interação entre os jogadores e o nível de informação que transmitem uns aos outros. De um lado o Governo ao 


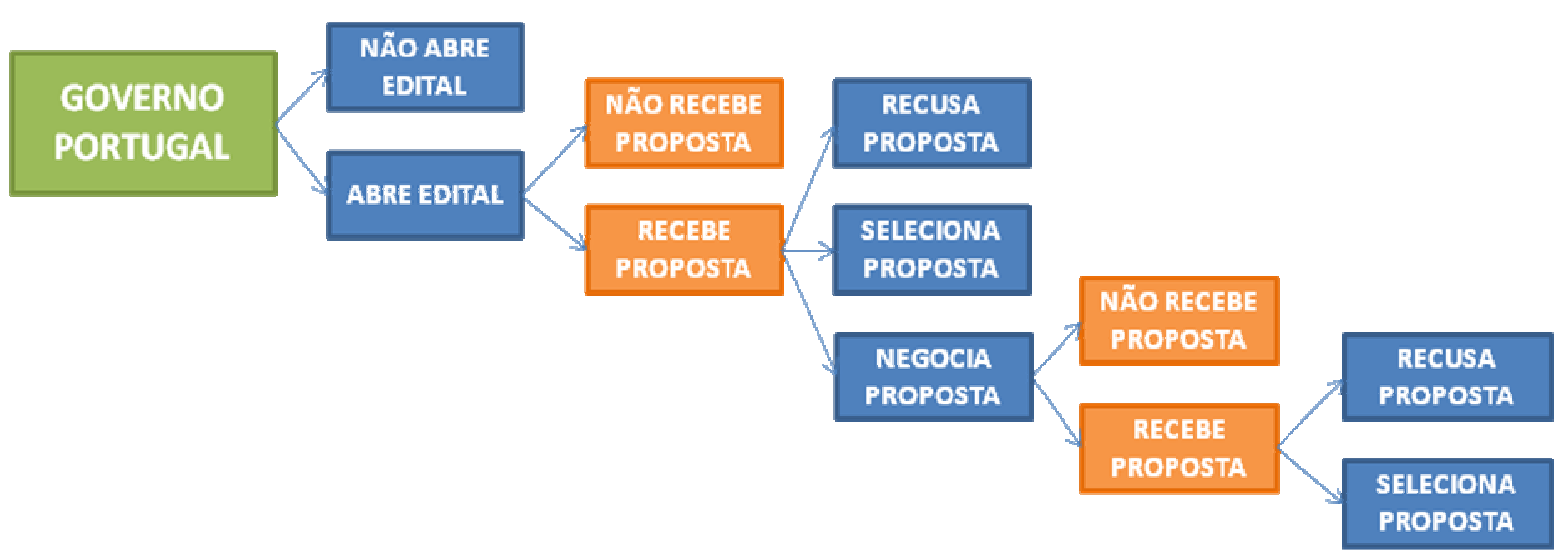

Figura 1 - Diagrama de decisão no jogo da reprivativação da TAP

abrir o edital disponibiliza a maior quantidade de informações da maneira mais clara possível, a fim de manter um processo de ética e transparência ao processo de privatização. Do outro lado, no momento do recebimento das propostas, o governo não conhece a índole das empresas, nem a veracidade das informações ali disponibilizadas. As empresas não trocam informações entre si. Pela sequiência das decisões e pelo fluxo de compartilhamento de informações, o processo de privatização da TAP é um jogo de informações assimétricas.

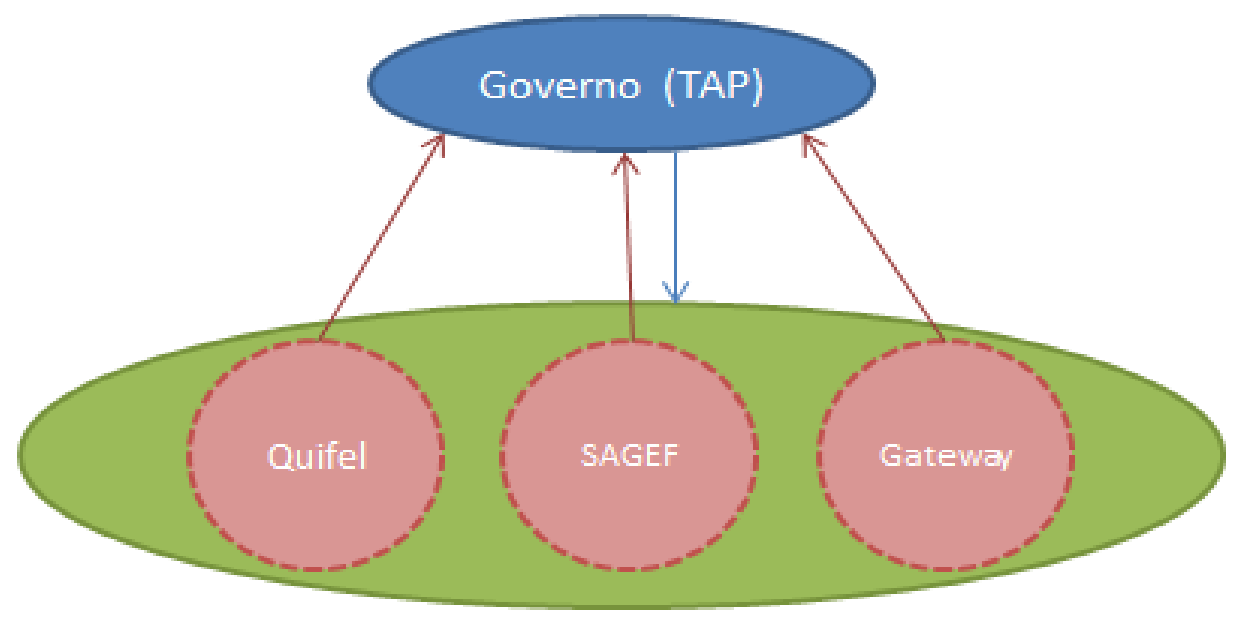

Figura 2 - Relação de interação entre os jogadores e fluxo de compartilhamento de informações

Além disso, com base nas definições de Leilões (seção 3.2), o jogo se assemelha a um leilão de demanda onde os compradores fazem um lance de demanda para comprar o bem que esta sendo ofertado - e fechado - pois os lances são feitos através de propostas que não são postas publicamente. Com relação ao valor do objeto, pode ser considerado um leilão híbrido, possuindo características tanto de um leilão de valor comum como de valor privado. É considerado de valor comum, pois o valor de mercado da TAP, além das dívidas e diversas informações financeiras são de conhecimento comum, disponibilizadas nos balanços da própria empresa que podem ser acessados facilmente no site da TAP. No entanto, quando analisado o valor da TAP considerando as ações e investimentos descritos nas propostas e o objetivo de cada jogador, a privatização se assemelha a um leilão de valor privado, onde a função de valor é subjetiva e envolve o sentimento do jogador com relação ao item. 
A relação entre o governo e as empresas é uma relação de cooperação, visto que, os jogadores têm um mesmo objetivo que se complementa Compra/Venda da TAP -, quanto observada a relação entre as empresas que visam a compra da TAP, identifica-se uma relação de competição, visto que estão disputando o mesmo bem.

\section{CONCLUSÃO}

Os aspectos da Teoria dos Jogos aplicados ao processo de reprivatização da TAP envolvemalém de diversos jogadores, dois ambientes de interação diferentes e específicas que ocorriam ao mesmo tempo. Nesse sentido, apesar de envolver situações de cooperação e competição, o jogo é dinâmico e de informação assimétrica, conforme discutido nas seções 3 e 4 .

A discussão deste artigo pode ser ampliada analisando outros processos de privatização dentro do setor de aviação, ou mesmo, outros métodos de compra/venda/fusão de empresas de aviação.

\section{REFERÊNCIAS}

COUTINHO, A.; ROCHA, A. \& GARCEZ, A. 2013Tap Air Portugal - A História da Companhia Aérea (19452013), $2^{a}$ Edição, Rio de Janeiro, Contra a Corrente.

DECRETO LEI 181A/2014 MINISTÉRIO DA ECONOMIA DIARIO DA REPUBLICA $1^{\text {a }}$ Série, $\mathrm{N}^{\circ}$ 248/2014, de 24/12/2014

$\begin{array}{llcl}\text { DECRETO } & \text { LEI } & 210 / 2012 & - \\ \text { MINISTÉRIO } & \text { DAS } & \text { FINANÇAS } & \text { - }\end{array}$ DIARIO DA REPUBLICA $1^{\text {a }}$ SERIE, $N^{\circ}$ 184, de 21/09/2012, Pág. 5335

\begin{tabular}{|c|c|}
\hline DESPACHO & $1156 / 2015$ \\
\hline ESIDÊNCIA DO & CONSELHO \\
\hline ROS & TEDO \\
\hline PRIMEIROMINISTRO & IO DA \\
\hline REPUBLICA $2^{\mathrm{a}}$ Série & ie, $N^{o} 24 / 2015$, de \\
\hline & 469A/2015 \\
\hline
\end{tabular}

MINISTÉRIO DAS FINANÇAS GABINETEDA MINISTRA - DIARIO DA REPUBLICA $2^{a}$ Série, $N^{\circ}$ 29/2015, de $11 / 02 / 2015$

$\begin{array}{ll}\text { DESPACHO } & 5119 \mathrm{C} / 2015 \\ \text { MINISTÉRIO } & \text { DAS }\end{array}$ GABINETEDA MINISTRA - DIARIO DA REPUBLICA $2^{\text {a }}$ Série, No ${ }^{\circ}$ 94/2015, de $15 / 05 / 2015$

\begin{tabular}{|c|c|}
\hline DESPACHO & $5638 \mathrm{~A} / 2015$ \\
\hline MINISTÉRIO & FINANÇAS \\
\hline GABINETEDA & MINISTRA - DIARIO \\
\hline $\begin{array}{l}\text { A REPUBLIC } \\
27 / 05 / 2015\end{array}$ & $2^{\text {a }}$ Série, $N^{\circ} 10$ \\
\hline
\end{tabular}

FIANI, R. 2009. Teoria dos Jogos, $3^{\mathrm{a}}$ Edição, Rio de Janeiro, Elsevier.

MYERSON, R.B. 1991. Game Theory: Analysis of conflict, Harvard, Harvard University Press.

TAP PORTUGAL. Acesso em 16 de Junho de 2015. Disponível em: $<\mathrm{http}: / /$ www.tapportugal.com/>

SHI,X. \& Vo $\beta, \quad$ S. 2011 Game Theoretical Aspects in Modeling and Analyzing the Shipping Industry.Computational Logistics, Lecture Notes in Computer Science, 6971,302-32. 